\title{
Como descrever uma "onda"? Uma abordagem metodológica para a etnografia de um movimento
}

How to describe a "wave"? A methodological approach to an ethnography of movement

\section{Karina Biondi}

\section{(2) OpenEdition}

\section{Journals}

Edição electrónica

URL: http://journals.openedition.org/aa/3300

DOI: 10.4000/aa.3300

ISSN: 2357-738X

\section{Editora}

Programa de Pós-Graduação em Antropologia Social (UnB)

\section{Edição impressa}

Data de publição: 1 dezembro 2018

Paginação: 285-308

ISSN: 0102-4302

\section{Refêrencia eletrónica}

Karina Biondi, «Como descrever uma "onda"? Uma abordagem metodológica para a etnografia de um movimento", Anuário Antropológico [Online], v.43 n.2 | 2018, posto online no dia 26 maio 2019, consultado o 28 abril 2021. URL: http://journals.openedition.org/aa/3300 ; DOI: https://doi.org/ 10.4000/aa.3300

\section{(c) $(1)(9)$}

Anuário Antropológico is licensed under a Creative Commons Atribuição-Uso Não-Comercial-Proibição de realização de Obras Derivadas 4.0 International. 


\title{
Como descrever uma “onda"? Uma abordagem metodológica para a etnografia de um movimento ${ }^{1}$
}

\author{
Karina Biondi \\ Universidade Estadual do Maranhão
}

Em 2012, ocorreu no Estado de São Paulo o que foi chamado por diferentes veículos de grande mídia de uma “onda de violência”. Após anos consecutivos de queda no número de homicídios, a capital paulista apresentou um aumento de 40\% com relação ao ano anterior. ${ }^{2}$ Conforme divulgado pela Secretaria de Segurança Pública, no total foram 4.836 mortes no Estado de São Paulo, 1.495 só na capital: 111 policiais e 19 agentes penitenciários (Sobrinho, 2013). Especialistas foram rapidamente convocados, pela imprensa, a explicar o que estava acontecendo e o porque da guinada na curva dos gráficos estatísticos. Foram diversas as explicações apresentadas, mas a grande maioria apontava para um confronto entre as forças policiais paulistas e o Primeiro Comando da Capital (PCC), coletividade originada no interior das prisões paulistas no início da década de 1990, hoje presente não só na grande maioria das instituições penais e zonas urbanas de São Paulo, como também em outros estados brasileiros.

Justamente durante esse período, eu estava em trabalho de campo para a minha pesquisa de doutorado sobre a atuação do PCC fora das cadeias. Neste artigo, apresentarei cinco cenas que, compostas por materiais etnográficos e trechos de reportagens da época, dão a tônica não só do tipo de material etnográfico com o qual trabalhei, como também de como o PCC se configura. A seguir, exporei algumas posturas metodológicas acionadas para dar conta desse material. Na medida em que apresentarei alguns dos termos centrais para o modo de existência do PCC (e também para minha escrita sobre ele), retomarei as cenas a fim de oferecer uma abordagem original acerca daquela "onda de violência”. Por fim, argumentarei que essa abordagem é capaz de colocar sobre outras bases a relação entre PCC e Estado.

Cabe adiantar que os termos nativos, tanto os que tornei centrais quanto os que os cercam e que estão presentes em todo o artigo, são essenciais para sustentar minha perspectiva teórico-metodológica. Com a intenção de conferir primazia ao material etnográfico, indissociável da exposição do modo como as pessoas sobre as quais escrevo refletem sobre suas próprias vidas na medida em que as conduzem, 
procurarei abordar de maneira positiva esse vocabulário, mesmo ciente de que alguns dos termos, quando vistos a partir de perspectivas outras, possam ser estigmatizantes. Minha opção, contudo, é alinhada a uma postura que está presente na tradição antropológica desde, ao menos, quando Boas (1920) abordou o potlach, quando Malinowski (1922) discorreu sobre o kula, ou quando Mauss (1924-1925) refletiu sobre as noções de mana e hau. Em alguns casos, trata-se de prezar pela particularidade do que está sendo dito. Em outros, de respeitar certa estética expressa nas falas. Existem, contudo, termos que, se traduzidos, ainda que no interior de nossa própria língua, descaracterizariam e simplificariam a complexidade daquilo que está em questão.

\section{Condições de pesquisa}

Por vários motivos, todos alheios à minha vontade, a minha pesquisa não foi realizada de acordo com os modelos consagrados de trabalho de campo, especialmente o que Stocking (1992) chamou de arquétipo malinowskiano de trabalho de campo. Raramente encontrei antigos conhecidos de minha pesquisa anterior (Biondi, 2010); muitos deles estavam presos, à época, e outros faleceram. Gastei mais tempo do que imaginava para inspirar alguma confiança nas pessoas que transitam no crime. $^{3}$ Algumas vezes, quando eu conseguia, elas eram presas. Outras vezes, o ritmo da quebrada $a^{4}$ mudava drasticamente e os meus anfitriões me mandavam embora. Ademais, mesmo quando me fixava em algum lugar, via que as coisas relativas àquela quebrada aconteciam também em outros lugares. Tudo isso me impeliu a transitar por várias regiões, tentando perseguir o meu tema de pesquisa. Nesse trânsito, deparava-me com situações tão díspares que me faziam sentir incapaz de oferecer algum tratamento e arranjá-las em torno de um texto acadêmico.

Para ilustrar o tipo de material etnográfico com o qual lidei, exponho a seguir cinco cenas ocorridas em 2012, quando ocorreu em São Paulo o que foi veiculado na mídia como uma "onda de violência", atribuída a um confronto entre o PCC e a polícia.

\section{Cena 1: Na conta da polícia.}

Iniciei minha pesquisa de doutorado em uma cidade do litoral paulista, em dezembro de 2011, com visitas esporádicas cujo objetivo era conhecer os ladrões ${ }^{5}$ da região e negociar com eles as condições nas quais eu desenvolveria meu trabalho de campo. Em abril de 2012, a imprensa passou a noticiar uma “onda de violência” na região: 
A nova onda de violência começou no dia 10, quando o PM Rui Gonzaga Siqueira, 46 , foi morto a tiros quando fazia um "bico" de segurança no Jardim Castelo. Depois da morte do PM, cinco moradores de bairros da região [...] foram assassinados por homens encapuzados que estavam em motos ou carros escuros. (...) Para investigadores, os últimos assassinatos podem ter sido cometidos como retaliação pela morte do PM. (Caramante, 2012a).

As execuções não cessaram, frequentemente outras eram noticiadas na mídia. No entanto, mesmo com todo o alarde da imprensa, o cotidiano da quebrada parecia pouco ter mudado. Diante desse quadro, em conversa com um dos irmãos (integrantes do PCC) de lá, uma colega tocou nesse assunto:

- Então, e essas mortes todas?

Edivaldo riu.

- É a polícia que tá matando, não é? - insistiu minha colega.

Edvaldo olhou para as demais pessoas presentes e, ainda rindo, respondeu:

- Ah! Se tão colocando na conta da polícia, tá bom.

Cena 2: $O$ salve ${ }^{6}$ chegou!

O mês de julho de 2012 teve início com matérias jornalísticas sobre uma "onda de violência” no Estado de São Paulo que teria começado em meados de junho:

Os números da onda de violência que atinge São Paulo, que já dura 20 dias, não param de crescer: até a tarde desta terça-feira (3), 17 ônibus foram incendiados no Estado e 11 bases de forças de segurança - dez da Polícia Militar e uma da Guarda Civil Municipal - foram atacadas a tiros. (...) As investigações não descartam a possibilidade de que os ataques sejam uma represália da facção criminosa PCC (...) a uma operação da Rota em maio, no qual seis supostos integrantes do grupo morreram - um deles foi morto à queima roupa, após sofrer tortura. A polícia trabalha com a possibilidade de os ataques serem uma resposta à transferência de um dos chefes do PCC para outra penitenciária. (UOL, 2012)

Dia após dia, novas matérias denunciavam a continuidade dessa "onda de violência”, apresentando números que, embora divergentes, apontavam a gravidade do que estava ocorrendo. Ainda que as reportagens não oferecessem uma data precisa (ou consensual) do início dessa “onda”, todas já contabilizavam as perdas e mencionavam a suspeita de esses ataques serem de autoria do PCC. Mesmo diante desse 
quadro, defini o início de estadia em campo para o dia 14 de julho. Afinal, a quebrada para onde eu seguiria parecia estar no seu ritmo habitual. Antes de seguir para lá, enquanto lia sobre o saldo atualizado dos ataques, um programa televisivo mostrava imagens de todos eles como se naquele dia o PCC estivesse iniciado uma ofensiva aos órgãos de segurança pública. Sabendo que as imagens mostradas não eram daquele dia, não me preocupei. Telefonei para a interlocutora que me receberia para avisá-la que estava a caminho e ela disse:

- Não vem não... Você não pode vir. O bagulho tá doido!

- Do que você tá falando? É do que tá passando na televisão? - perguntei.

- É, chegou o salve. O bagulho vai endoidar.

- Mas isso que tá passando não é de hoje. Vem acontecendo faz uns dias - ponderei.

- Não é só isso, não. Tô falando pelo que chegou aqui. Não é só a televisão, não. É uns negócios que fiquei sabendo por aqui. Chegou o salve!

Cena 3: Os irmãos sumiram.

Diante da recusa de minha interlocutora em me receber naquele momento, fui em busca de outro lugar onde pudesse realizar a pesquisa de campo. Em outra quebrada, puxei conversa com um correria ${ }^{7}$ que não era irmão:

-Tô sabendo que chegou um salve pros ataques...

- Então! Parece que o salve tinha chegado só até a quebrada Z, não chegou até aqui, não - me disse o correria.

Fiquei pensando de que direção teria vindo o salve e qual teria sido o caminho percorrido para ter parado naquela quebrada, mas logo percebi que essas questões eram descabidas para tempos em que todos usam telefones celulares. Perguntei, então:

- Quer dizer que o salve não chegou aqui?

- Ah! Antes de chegar, os irmãos sumiram. Eles sabiam que mais cedo ou mais tarde o salve chegava, porque já tinha chegado na quebrada Z. Então eles deram no pé.

Dois meses depois, ainda com os irmãos sumidos, a imprensa noticiou o assassinato de um policial naquela quebrada. 
Cena 4: Salve de 15 dias.

Na semana seguinte, uma amiga me apresentou uma quebrada onde fui muito bem recebida e a realização da pesquisa foi aceita com empolgação. Na conversa com o malandro ${ }^{8}$ com quem combinei as condições da pesquisa, perguntei sobre os ataques que, conforme eu lia na imprensa, continuavam acontecendo intensamente:

- E o salve pros ataques?

- Não tem mais.

- Mas chegou o salve?

- Chegou, mas acabou. Foi só 15 dias.

Cena 5: É fita pessoal.

Em maio de 2012, os jornais anunciavam: "Rota mata seis e PMs são presos suspeitos de execução” (Jozino, 2012). No mês seguinte, outras matérias noticiavam a morte de policiais naquela região:

Três policiais militares foram mortos a tiros na zona leste de São Paulo em apenas sete dias. (...) Existe a suspeita de que as mortes dos três PMs tenham sido retaliação da facção criminosa PCC contra a operação da Rota (tropa de elite da PM) que matou seis homens no fim de maio, também na zona leste de São Paulo. (Caramante, 2012b)

Em meados de agosto de 2012, soube que saíra da cadeia um interlocutor que morava na região em que o tiroteio aconteceu. Fui ao seu encontro e, durante a conversa, comentamos sobre o que ocorrera:

- Ah, então, doutora! Eu cheguei lá e perguntei: "O que aconteceu, que fita foi aquela que morreu os caras”. Daí me disseram que os policiais chegaram lá atirando. O bagulho foi doido...

- Mas depois disso, eu fiquei sabendo que rolou um salve pra matar os policiais comentei.

- Não, isso não é do Comando, ${ }^{9}$ não. Não teve salve. Foi um cara ou outro que se revoltou e resolveu ir atrás. É fita pessoal, de quem acha que não tá certo, que se revoltou com os policiais. Os policiais tão matando pra caramba, doutora.

- Mas me disseram que chegou salve lá na quebrada X, na quebrada Y...

- Ah, mas aqui não chegou, não. 
Policiais assassinados onde o salve não chegou, mortes 'na conta da polícia', um salve que só chegou depois de um mês do início da "onda de violência”, justamente quando, em outro lugar, ele já havia perdido sua data de validade, irmãos que fogem do salve: eram essas situações díspares que conformavam o que se chamou de "onda de violência”, explicada por especialistas, como mencionei acima, como um confronto entre PCC e polícia. Mas disparidades como essas não são eventuais no meu material etnográfico. Pelo contrário, ele é constituído por uma coleção de dados tão díspares que parecem se contradizer. Em outras palavras, meu material etnográfico não se diferencia, em termos de coerência, das cenas que ilustram a "onda de violência” de 2012. Isso me colocou diante de duas questões. A primeira, de teor teórico-metodológico, refere-se aos recursos passíveis de serem mobilizados para a etnografia de uma “onda”. A segunda questão, concernente ao tema de pesquisa, diz respeito a como oferecer alguma explicação no seio de um debate que colocava os acontecimentos em termos de uma guerra entre duas forças coesas, duas unidades monolíticas.

\section{Posturas metodológicas}

A fim de conciliar dados aparentemente tão contraditórios uns aos outros e oferecer um tratamento à "onda de violência” de 2012, proponho algumas posturas metodológicas para lidar com esse material. A primeira é rejeitar que os próprios irmãos ignoravam o que estava acontecendo. Eles não só sabiam, como eram eles mesmos os protagonistas do que, posteriormente, era notícia na imprensa. Em outras palavras, eles faziam tudo aquilo acontecer. Esse ponto foi evidenciado por um ladrão, durante interrogatório feito por policiais e publicado pela imprensa:

Policial civil - Explique desde o começo como foi a "caminhada” (as missões a serem cumpridas).

Interrogado - O salve (a ordem) chegou pra mim. Eu já tinha ciência do salve. Eu recebi o salve e passei pros irmão concluir (matarem). O salve é das injustiça que tava tendo, que a Rota tava matando e forjando. E a caminhada é que cada região tá concluindo um $\mathrm{PM}$.

Policial civil - E qual era o prazo que vocês tinham para executar os PMs?

Interrogado - Era dez dias. Só que nisso aí foi brecado o salve devido aos cara tá 
matando muita gente inocente. Até faleceu PM que trabalhava na parte interna. Tavam dando tiro na viatura, coisa que não era pra acontecer.

Policial civil - O que era para ser feito. Qual era a missão, então?

Interrogado - As ideia não era essa. As ideia era cada injustiça que a Rota fosse fazer. Não atitudes isoladas e pegar PM fazendo bico. A caminhada era pra atingir a Rota. Não pra atingir os PMs que trabalham na parte interna e fazendo bico e nem PM nenhum fardado.

Policial civil - Quando você fala (ao telefone, que está grampeado) que o prazo tá vencendo que já tá vindo cobrança e você fala, vamos catar qualquer pingaiada (qualquer policial) que tá por aí....

Interrogado - Eu me lembro dessas ideia, só que não foi eu que falei essa situação. Essa situação chegou em mim e eu até brequei. Falei, não é desse jeito, não.

Policial civil - Se era pra matar um por quebrada porque vocês estavam atrás pra matar mais?

Interrogado - Não. Eu tava na ordem do salve correto. Que chegou até nós. Era um só. ${ }^{10}$ (Delphino, 2012).

Essa poderia se somar às cenas expostas acima e, ainda assim, só adicionaria mais uma disparidade. Embora a imprensa (e, talvez - porque não ficou claro na reportagem -, a polícia) tenha extraído uma "confissão da falta de comando" (idem, 2012), o que essa fala mostra com clareza é a consciência e a certeza do depoente com relação ao que estava fazendo. Para ele, aquilo nada tinha a ver com falta de comando, mas, sim, com a circulação de ideias divergentes. Não parecia haver também lacunas na informação, algo que só faz sentido quando o que se espera é encontrar totalidades coesas. Para os ladrões, eles não habitam alguma totalidade desse tipo, mas compõem um movimento.

A segunda postura metodológica para lidar com meu material etnográfico é encarar que eu só poderia descrever o Movimento a partir de seu interior. Abordarei o movimento mais detidamente adiante. Por ora, basta adiantar que ele se caracteriza, por um lado, pela ausência de delimitações temporais, de contornos espaciais, de limite quanto ao que pode compô-lo e, por outro, por ser fugidio a qualquer tentativa de totalização e por ser composto por inúmeros outros movimentos. Ao me movimentar em seu interior, pude vê-lo, não como uma série de acontecimentos desconexos ou como uma totalidade repleta de contradições, lacunas e inconsistências, mas como o resultado de uma maneira singular de 
conceber o mundo. Na verdade, meu salto para o interior do movimento não foi planejado ou calculado. Eu só percebi estar instalada no interior desse movimento quando me vi lá. Mas, dali, vi que aquela posição não implicava ser algo, não remetia a uma espécie de identidade. Eu permanecia uma diferença, alguém que, embora no movimento, viera de fora. Ali, eu não via exatamente o que os malandros viam, mas podia ver as coisas da forma como eles viam.

A terceira postura metodológica é dedicar-me a expor o que vi e assumir que as diferenças que enxergava por todos os lados, mais do que constituírem contradições a serem denunciadas ou superadas, precisam ser descritas. Isso não mais me permite falar a partir do ponto de vista dos nativos, o que poderia conduzir à homogeneização dessas diferenças. A descrição do PCC aqui apresentada expõe o meu ponto de vista no interior do Movimento, uma posição que só pôde ser assumida porque me permiti saltar para seu interior. Descrever o meu próprio ponto de vista, a partir do interior do movimento, permite enxergar que as diferenças que se apresentam são manifestações de uma forma singular de conceber essas próprias diferenças.

A quarta postura metodológica é procurar meios para não trair, na escrita, o que acessei em minha experiência de campo e, por conseguinte, procurar desenvolver uma escrita que não traia o movimento. Para tanto, procuro evitar a subordinação de meu material etnográfico a contextos mais amplos e rejeitar, assim, as determinações produzidas por essas contextualizações. Isso não implica, obviamente, o isolamento do objeto de pesquisa. Afinal, um movimento não aceita limitações. Diferentemente, minha proposta, inspirada em Strathern (2004), é justamente acompanhar sua expansividade sem posicioná-lo ou enquadrá-lo no interior de um contexto. Liberar o movimento de sua contextualização para mostrar as conexões que ele próprio traça me leva também a libertar minha escrita dos direcionamentos que acompanhariam sua inserção no debate corrente sobre crime. Isso porque o debate público coloca questões em torno das quais as produções gravitam, questões que, algumas vezes, são exteriores ao material etnográfico que norteia meu trabalho. Se, por um lado, evito ter minhas reflexões pautadas pela literatura especializada (o contexto da escrita, pode-se dizer), por outro, ela é acionada a partir das discussões levantadas por meu material. Dessa forma, a fim de procurar não trair o movimento, evitei tanto o contexto do objeto quanto o da escrita para realizar conexões a partir dele próprio.

A última postura metodológica para lidar com o meu material está ligada à seguinte dificuldade: cada partícula de meu material etnográfico contém todo o 
material. Isso porque cada termo utilizado pelos ladrões só funciona com os outros, quer dizer, eles não só remetem uns aos outros como se requisitam, em constante apelo recíproco. Aciono, então, duas estratégias. A primeira é colocar os termos que expressam noções não só usadas, mas, principalmente, vividas pelos ladrões como centro de minhas descrições. A segunda é o bloqueio de alguns dos termos que orbitam os que eu descrevo, a fim de tornar esses últimos mais evidentes. $\mathrm{Na}$ medida em que são descritos, desbloqueio outros que se somam e se conectam a eles. Nenhum deles, porém, está ausente, mas apenas ocultado pela sombra formada pela luz que eu lanço sobre o que descrevo. Disso resulta, em primeiro lugar, o fato de que este artigo não aborda os vários aspectos do PCC, mas sempre elementos que remetem e requisitam uns aos outros. Em segundo lugar, o Comando não é apresentado a partir de seu contraste com algo exterior a ele. Mesmo quando alguns contrastes são acionados para evidenciar a particularidade das noções apresentadas, eles partem do próprio léxico utilizado pela malandragem. Não se trata, particularmente, de opor PCC a Estado (de uma comparação entre duas totalidades, portanto). Trata-se, antes, de evidenciar as conexões realizadas a partir do interior do movimento, de mostrar, inclusive, como práticas estatais são feitas movimento.

Em suma, para lidar com um material etnográfico tal como o exemplificado nas cenas acima, abordei o movimento a partir de seu interior, da visão que eu tinha ali de dentro, sem pretender falar em nome dos outros que ali se movimentavam e que, sem dúvida, eram os maiores conhecedores das práticas que me esforço em descrever, mas conferindo centralidade aos termos que eram decisivos nesse movimentar, deixando que as conexões fossem realizadas a partir do que ali importava e não limitadas por um contexto anterior e exterior a ele.

De fato, essas posturas metodológicas trazem para o centro de minha exposição termos que, ao longo de minha pesquisa, mostraram-se centrais no modo de existência do PCC. A seguir, os termos movimento, ideias, ritmo, hierarquia e lei, trabalhados em detalhes em Biondi (2018), serão apresentados suscintamente de forma a se relacionarem com as cenas expostas acima, colocando em outros termos as diferenças nelas expressas.

\section{Movimento}

Poucas foram as ocasiões nas quais ouvi os malandros chamarem o PCC de movimento. Entretanto, essa foi a brecha encontrada para explorar analiticamente o próprio PCC. Ao invés de tentar preencher lacunas de modo a colmatar o que eu mesma 
concebia como uma falta em relação a um todo e assim encontrar explicações para a falta de coerência que se revelava em meu material etnográfico, procurei entrar nas brechas, ali me instalar e trabalhar nelas.

Do interior do movimento, vi que, longe de constituir uma unidade monolítica, o PCC não só comporta como também é constituído por vários movimentos que apresentam diversas formas, calibres, velocidades e rumos. Pessoas, situações, telefones, relações afetivas, ideias, lutas, vidas, mortes, quebradas, transações comerciais, não há restrições quanto ao que pode compor os movimentos. Mas essas composições são sempre momentâneas. Se os movimentos ganham vida com esses elementos, eles logo os deixam para acoplar outros elementos que passam a compô-los, não sem imprimir seus rastros. Ademais, eles não se conformam a espaços ou a intervalos de tempo, pois não têm origem e nem fim definidos. Em decorrência disso, o Comando não se limita às trajetórias das pessoas, mesmo às dos irmãos, e nem permanece confinado em redutos.

No intenso fluxo de movimentos simultâneos constituintes do PCC, eles se cruzam, convivem, disputam, acoplam-se, tensionam uns aos outros. Isso leva cada um que transite pelo seu interior a compor simultaneamente vários movimentos, mas também a saltar constantemente de um a outro. De cada uma das posições assumidas nesse fluxo, emerge um ponto de vista singular. Nenhuma perspectiva é idêntica à outra: os movimentos vistos por um estão ocultos para outros, e vice- versa. Nesse trânsito, é inevitável que movimentos sejam perdidos de vista ao mesmo tempo em que outros apareçam. Isso não quer dizer, entretanto, que eles só sejam apreensíveis fragmentária ou parcialmente, pois partes e fragmentos só fariam sentido em relação a um todo que supostamente um dia compuseram, do qual se desprenderam ou ao qual estão submetidos. ${ }^{11}$ Diferentemente, os movimentos não são uma unidade natural pronta a ser apreendida, parcialmente ou em sua totalidade, seja por mim, seja por meus interlocutores. Eles são exatamente o que os diferentes pontos de vista são capazes de apreender. Assim, a composição, o formato, a força e a extensão adquiridos pelo movimento dependem do ponto de vista adotado.

Portanto, não há no PCC caminhos definidos rumo a uma missão ou objetivo comum por meio dos quais as coisas concorram, todas juntas. Não há, em uma palavra, teleologia. Tampouco há unidade, organização, estruturação. Sob essa ótica, as cenas que expus nada tinham de visões parciais de um todo ou de informações cheias de lacunas, pois a composição do movimento depende da perspectiva 
adotada. Se ele não tem origem ou fim definidos é porque ele é exatamente o que se faz dele a partir da visão que se tem desse e de outros movimentos, ou melhor, do arranjo que compõe as situações. Dessa forma, meus interlocutores não expressavam outra coisa senão o movimento como vislumbrado por eles próprios quando, simultaneamente, o compunham. Se, a despeito de como é percebido, ele só ganha existência graças a quem o constitui, é possível ver o movimento como o resultado de um jogo de forças, de tensionamentos constantes, decorrentes dos esforços dos malandros em imprimir rumos que lhes pareçam mais favoráveis. Nesse sentido, não só a "onda de violência” como também cada movimento que a compôs podem ser pensados como resultados desses esforços.

\section{Ideias}

Se os movimentos são tão fugidios a ponto de passarem pelos malandros e seguirem a perder de vista, de não obedecerem a restrições espaciais ou a limites temporais, de aceitarem o que a ele se acopla sem qualquer prescrição, como é possível tentar conduzir seus rumos? Em primeiro lugar, cabe lembrar que a malandragem compõe o movimento ao mesmo tempo em que confere a ele existência. Em segundo lugar, entre tudo o que pode se movimentar, há um elemento invariavelmente presente: as ideias.

Mas elas são mais do que apenas um dentre os elementos ou componentes do movimento. As ideias chegam a se confundir com ele. A diferença entre eles é que o movimento é a ideia somada a tudo o que ela mobiliza, permite ou com o que a ela se acopla. Se, invariavelmente, os elementos moventes vêm acompanhados (ou a reboque) das ideias, elas são constantemente criadas, produzidas e mobilizadas pelos ladrões a fim de manter, nutrir, conduzir, fortalecer, propagar, alterar os movimentos.

Na malandragem, a noção de ideia nada tem a ver com pensamento, formulação ou invenção. Nunca se diz 'eu tive uma ideia'. Somente quando se tornam manifestas, elas passam a ganhar existência e apenas quando se desprendem de seus locutores e tomam rumos diversos aos dele (quando se tornam movimentos), as ideias passam a ter importância na malandragem. Em outras palavras, elas só existem quando em fluxo pelo mundo, quando compartilhadas. Nesse ponto, elas passam a ser, ao mesmo tempo, centros de convergência de forças que disputam seus rumos e as fontes que oferecem direção e conferem atributos aos movimentos. Desse modo, elas assumem uma existência própria: sem deixar de ser resultado das forças que 
incidem sobre elas, são também capazes de constranger essas forças. Além disso, se por um lado as ideias não têm vínculos profundos com seus locutores, por outro, elas se vinculam a qualquer um que as manifesta, que as faz repercutir. Ao invés da noção de autoria, as ideias são acompanhadas por uma noção de responsabilidade. Cada um que as manifesta se torna responsável por elas. Assim funcionam os avais, as autorizações consentidas (por exemplo, para minha estadia na quebrada a fim de fazer pesquisa). Ideias que são, cada um que os profere assume a responsabilidade por eles. Já os salves, por sua vez, são ideias atribuídas ao Comando, independente de quem os repercute ou como isso ocorre.

Desse modo, ideias um dia tratadas como de mil grau (de suma importância e urgência) noutro dia simplesmente desaparecem. Recentemente (Biondi, 2018), pude abordar esses desaparecimentos como resultados das forças empenhadas para fazer ideias morrerem, para enterrá-las. Isso evidenciou também o esforço dos ladrões para mantê-las ativas, para fazê-las vencer, para fortalecê-las, mas também as estratégias implicadas na (e para) sua desativação e retomada. Mas vi, também, que o desaparecimento de uma ideia ocorre quando ela deixa de ser repercutida. Isso porque, se as ideias ganham importância a partir de sua manifestação, é com sua repercussão que elas se mantêm vivas. Para tanto, é indispensável que esforços sejam engajados nesse sentido. Afinal, nenhuma ideia sobrevive por inércia. Nem mesmo o próprio PCC, que, nesse sentido, obedece a essas mesmas dinâmicas. Como as ideias, o PCC é também incessantemente alimentado ao passo que é expresso nas falas e nas ações mais triviais, mais cotidianas. Cada ideia no interior do Movimento obedece a essa mesma dinâmica. Depois de lançada, repercute quando os malandros abraçam-na e a manifestam. Para que ela permaneça viva, é necessário fortalecê-la, ou seja, fazê-la repercutir. Por outro lado, há formas de desativar ideias, colocando-as no gelo, ou fazê-las desaparecer, enterrando-as ou, simplesmente, empenhando-se para que elas deixem de repercutir.

Sendo assim, não é de se estranhar que o salve, como ideia que é, se movimente de maneiras tão diferentes nas cenas apresentadas. De fato, durante toda a minha pesquisa, pude notar que os salves não chegam em todos os lugares, que, quando chegam, eles podem apresentar conteúdos diferentes, que sua chegada não ocorre ao mesmo tempo em todos os lugares e que, por fim, eles nem sempre são aceitos ou efetivados. 


\section{Ritmo}

Se a existência das ideias está condicionada à sua repercussão, cada vez que expressadas, elas recebem as marcas tanto da ocasião na qual isso ocorre, quanto daquilo que mobilizam para comporem um movimento. Ademais, sobre elas incidem forças que influenciam sua manutenção, transformação, fortalecimento; ela é o resultado desses embates. Disso decorre que, em primeiro lugar, as ideias sempre comportam mudanças; trazem consigo a possibilidade sempre iminente de transformação. Em segundo lugar, as manifestações das ideias não ocorrem sem imprimirem nelas suas condições situacionais.

A cada manifestação, a ideia é revestida pelas condições situacionais nas quais ocorre e, por conseguinte, sofre uma variação com relação à manifestação anterior. Isso faz com que até as ideias mais gerais, como a Paz, a Igualdade ou o próprio PCC, recebam as marcas das condições locais de sua manifestação e variem de acordo com essas condições. Às variações apresentadas, os ladrões denominam ritmo, nome dado também às próprias condições que revestiram a ideia e fizeram-na variar. Ritmo, assim, diz respeito tanto às condições particulares que se acoplam às ideias quanto à variação resultante, que passa ela própria a compor a nova situação que pode fazer outras ideias variarem. Essas variações não se devem exclusivamente ao modo pelo qual uma ideia é incorporada ao ritmo local, mas também a que ideias chegam a ele, ou seja, à chegada de algumas ideias enquanto outras não chegam. Afinal, estão nos próprios ritmos as condições de possibilidade para a chegada de uma ideia.

Quando partimos dessa perspectiva, é possível colocar em outros termos (que não os da falha, da desordem ou da falta de comando) as diferenças apresentadas nas cenas com relação à chegada e encaminhamento dos salves. Não se trata, assim, de uma estrutura falha, de uma ordem abalada ou de perda de coesão, mas, sim, de ideias que se movimentam por ritmos os quais variam com elas, mas também as fazem variar e constrangem os caminhos pelas quais repercutem.

\section{Hierarquia}

A dinâmica das ideias está relacionada com a projeção dos próprios ladrões que nela se empenham. Ao ganharem força na medida em que suas ideias repercutem e se fortalecem, suas ideias revestem-se da força que os ladrões têm. Assim, não é raro ver que o malandro fortalecido pelas mesmas ideias as quais se empenhou em fortalecer assuma uma posição de destaque indissociável, por sua vez, de suas habilidades em lidar com as ideias. São esses os que conseguem impor seu ritmo. Mas essa imposição 
nada tem a ver com impor ideias e, sim, com a semeadura delas no âmago do ritmo vigente. Uma ideia precisa ser atraente e vantajosa para ser abraçada e, por conseguinte, repercutida. Para tanto, ela precisa ser lançada a partir das próprias condições situacionais correntes, ser interior às próprias circunstâncias nas quais se manifestam. Só ideias (feitas) imanentes ao próprio ritmo são capazes de alterá-lo. Afinal, ideias impostas são vistas como algo que não se convém abraçar; elas não repercutem e nem se fortalecem. Essa dinâmica conduz à rejeição de qualquer relação de mando que, por suposto, indique a incidência de ideias exteriores às correntes.

Em certo sentido, isso se conecta com o que Deleuze (1992 [1985]) fala dos novos esportes (surfe, windsurfe, asa delta). Neles, a questão não está mais nas fontes do movimento ou nos pontos de alavanca, mas na "inserção numa onda preexistente" (: 151). Para Deleuze, já não é uma origem enquanto ponto de partida, mas uma maneira de colocação em órbita. O fundamental é como se fazer aceitar pelo movimento de uma grande vaga, de uma coluna de ar ascendente, "chegar entre" em vez de ser origem de um esforço. (ibid.: 151)

Os malandros que se sobressaem aos outros, nesse sentido, não se destacam pela força bruta ou por estarem bem situados em uma suposta estrutura hierárquica. Pelo contrário, são aqueles cuja visão, responsa e conhecimento os tornam mais hábeis em fazer suas ideias repercutirem e se fortalecerem, ao mesmo tempo em que o alcance e o calibre adquiridos por essas ideias os fortalecem. Para os malandros, o termo conhecimento nem sempre tem a ver com a obtenção de informações, a construção de saberes, com a compreensão ou o entendimento de algo. Também não remete, sempre, à separação de um sujeito do conhecimento e um objeto a ser conhecido ou compreendido, implicada na definição apresentada por Lalande (1999). Na maior parte das vezes, na malandragem, ter um conhecimento é, do interior do movimento, estar conectado a muitos outros ladrões, é nutrir relações com um grande contingente de malandros. Esse sentido de conhecimento está relacionado às conexões estabelecidas de modo a dispor do número mais amplo possível de meios pelos quais se pode fazer as ideias fluírem. Diz respeito, assim, a ter conexões que permitam não só levar a ideia adiante como, principalmente, conferir um rumo adequado ao movimento que ela carrega.

O termo visão, por sua vez, não se restringe à percepção óptica proporcionada pelos mecanismos fisiológicos e neurológicos do corpo. Para os ladrões, 'um cara de visão' é aquele que melhor percebe a disposição dos movimentos, bem como seus rumos e entrecruzamentos. Por conseguinte, 'quem tem uma visão' é capaz de 
avaliar as ideias mediante a posição que assume no fluxo de movimentos. É recorrente ouvir os ladrões dizerem que 'os caras de visão conseguem sentir a maldade no ar', que eles são capazes de 'se antecipar', que eles têm 'um sexto sentido forte' . Quem tem visão é também hábil em avaliar os ritmos e se colocar no ponto de vista dos outros ladrões, o que facilita que lance ideias que lhes pareçam atraentes, com maior possibilidade de serem abraçadas e repercutirem. Quem tem visão é, ainda, alguém capaz de argumentar bem. Assim, não raro é, também, um bom orador. Por fim, de acordo com os malandros, 'um cara de visão é também um cara inteligente, informado'. Finalmente, a noção de responsa, antes de constituir instâncias de poder coercitivo ou relações de mando e obediência, vem acompanhada, como o próprio nome sugere, da responsabilidade de conduzir as situações com as quais os ladrões se defrontam.

Essas habilidades de visão, conhecimento e responsa são centrais no fluxo das ideias e na noção de hierarquia no PCC, que não pode ser abordada de outro modo senão no interior da dinâmica das ideias, adquirindo um sentido bastante diverso dos atribuídos a essa palavra, seja durante as comunicações corriqueiras, nas instituições ou nas Ciências Sociais. De fato, no PCC, a noção de hierarquia se distancia de seus sentidos mais comuns (seja como encadeamentos de mando e obediência, seja como ordem de importância ou de status, seja como disposição ou posicionamento das coisas em um todo), em direção ao que a malandragem chama de sintonia.

Para tornar as ideias que lançam imanentes aos ritmos dos que a abraçam, os malandros estabelecem, com eles, sintonia. Encontram, dentre a infinidade de movimentos disponíveis, um ou alguns com os quais possam se engajar. Não se trata, nesse caso, de compartilhar - ou partilhar, ou dividir - um mesmo movimento. Mas somar-se a eles, estar junto, 'na mesma caminhada'. Alguns irmãos, geralmente os que já demonstraram suas habilidades de levar suas ideias adiante, têm a sintonia como responsa. A despeito do nome que elas recebam (disciplina, geral, frente, palavra, piloto, torre, terminal, final, sintonia), essas responsas nunca denotam lideranças com poder de mando. Diferentemente, por serem irmãos de responsa, assumem responsas no Comando e, com isso, se tornam uma espécie de ponto de convergência dos movimentos que compõem o PCC. Quem está na responsa, nesse sentido, engaja-se em múltiplos movimentos, tanto ao tornar suas ideias imanentes às situações (e não ordens externas a elas ou, simplesmente, imposições), quanto ao ser um ponto de convergência dos movimentos atraídos por sua força e pela visibilidade que acompanha o exercício das responsas. Esses malandros que estão na responsa estão também em sintonia, a 
ponto de serem, eles próprios, denominados sintonias.

A sintonia, nesse sentido, não consiste em uma homogeneização das diferenças ou em um poder exterior aos movimentos a impor-lhes rumos. A noção de sintonia remete, justamente, ao engajamento nos mesmos movimentos, a estar na mesma caminhada sem, contudo, promover a identidade ou a homogeneidade. Ela é feita da soma de diferenças, cujo resultado não é outro senão outra diferença. Essa soma, diferentemente de uma partilha, permite que as ideias assumam diversas expressões e manifestações, resultados de suas transformações e adaptações, e se manifestem em diversos ritmos. Nesse sentido, sintonia não é uma relação exterior a termos pré-existentes ou um elo entre os diversos ritmos; ela ocorre juntamente às conexões das quais os ladrões participam, às somas que realizam e aos ritmos nos quais se expressam. Ao mesmo tempo em que produz e garante a preservação de diferentes ritmos, ela oferece as possibilidades para as ideias fluírem em meio a uma infinidade de movimentos, ora tensionando-os, ora ignorando-os, ora capturando-os, ora instalando-se neles.

Assim, sintonia confere paridade às diferenças de ritmos ao permitir que as expressões da hierarquia do Comando não sejam outra coisa senão o resultado de ideias que fluem por incontáveis movimentos, sem determinação prévia e cuja força e alcance variam de acordo com a visão, o conhecimento e a responsa dos intervenientes. Com isso, a hierarquia, no âmbito do PCC, não é disposta no espaço e nem segue critérios geográficos. Ela se atrela às dinâmicas que envolvem as ideias e é absolutamente condizente com o fluxo de movimentos.

A atenção à inexistência de uma figura hierárquica capaz de impor ideias ou de um centro de poder de onde partiria um único e inequívoco salve, bem como à dinâmica por meio da qual cada manifestação das ideias implica uma transformação (ao se acomodar e se incorporar ao ritmo local), faz com que não fiquemos mais tão perplexos com relação às disparidades apresentadas nas cenas expostas acima. A diversidade dos salves que circularam durante a "onda de violência" não expressava cisões ou divisões internas ao PCC, mas a composição de heterogeneidades, o engajamento de diversos ritmos nesse movimento, sintonizados pelo próprio Comando.

\section{Lei}

Essas bases móveis em que as concepções mais tradicionais de hierarquia não encontram morada também repelem a noção de lei, os modos de pensamento que 
a sustentam e o que dela deriva, além de todas as suas vizinhas semânticas, como norma, regra, código. Ainda que a malandragem tenha em seu léxico termos como justiça e lei (do crime), eles não são outra coisa senão um recurso metafórico que visa aproximar diferenças muito patentes. Isso porque, se de um lado vemos a ligação de Estado, Lei e Capitalismo em torno de práticas de conhecimento legalistas voltadas à regulação social, de outro lado, encontramos a luta incessante pelo certo indissociável das noções de justiça, ética, disciplina, subsumida nas dinâmicas dos movimentos e nas ideias.

Mas as considerações acerca do certo requerem uma certa estabilização dos movimentos, a que a malandragem dá o nome de situação. As situações podem ser definidas como um arranjo de movimentos apreendidos a partir de um ponto de vista, o que indica que se trata de uma estabilização em constante transformação. É importante lembrar que, como afirmei anteriormente, cada um desses termos não só remete aos demais como também só funciona com os outros, em meio a eles.

Nessa dinâmica, o certo nunca é definido de antemão: ele é formulado e expresso por meio de ideias e mediante cada situação, cada guinada de movimento. Não há um código que se inscreva, recubra ou determine os movimentos e nem uma ordem a ser mantida, mas um certo formulado sempre contingencialmente a se fazer prevalecer. Assim, se o certo só ocorre no interior de cada situação, quer dizer, em cada arranjo de movimentos apreendido a partir de um ponto de vista, ele é suscetível a mudanças a cada mirada, a cada deslocamento no interior do movimento. As situações constituem também a base para os debates, ${ }^{12}$ ao mesmo tempo em que são transformadas no decorrer deles. Aponto, com isso, que os debates nunca têm um fim determinado e nem assumem formas completas ou fechadas. Se isso já os distingue dos tribunais, o principal contraste está, contudo, nas bases em que ambos se assentam.

Pelo mesmo motivo, os salves não são recebidos da mesma forma em todos os lugares. Afinal, longe de terem status de leis que devam ser cumpridas à risca, eles são mais bem definidos como orientações, recomendações, comunicados que não só resultam de muitos debates sobre situações encontradas como também não fazem cessar as discussões sobre as situações resultantes. Se uma situação ou um conjunto delas são as bases para a elaboração dos salves, eles são recebidos em outras situações, nas quais passam a se articular com outras ideias e são acomodados aos ritmos locais. Assim, os salves são capazes de transformar, mas não de determinar, enquadrar ou modelar as situações. Ademais, eles nem sempre são incorporados ao ritmo local, 
especialmente quando encontram situações que o repelem. Mas quando chegam, os salves produzem novas situações ao serem recebidos, transmitidos e efetivados conforme a configuração que o recebeu e os efeitos que sua chegada produziu.

É possível dizer que cada uma das cenas apresentadas acima é a descrição de situações que, junto às outras, compõem o que se chamou de "onda de violência". A circulação de diversos salves durante esse período apenas evidencia as transformações pelas quais passam ao moverem-se por meio da e imiscuírem-se na sintonia mantida por cada ritmo com o Comando. A malandragem que aparecia em cada uma das cenas, embora movimentasse salves distintos entre si, estava pelo certo. E o certo, antes de remeter a um predicativo, indica um método, algo relacionado com um fazer-PCC.

\section{Considerações Finais}

Dificilmente minha perspectiva satisfaria aqueles que tanto procuraram explicações acerca da “onda de violência de 2012". Mesmo porque, como afirmou Villela, não me é "legítimo, como antropóloga, asseverar e nem sequer postular um problema que não aflige aqueles que foram a sua fonte dos dados da pesquisa” (2010: 14) e, definitivamente, formular explicações sobre o que estava acontecendo não era o escopo dos meus interlocutores. Ademais, é importante enfatizar que “onda” foi uma nomeação que apareceu nos jornais, não nas falas das pessoas com as quais convivi durante minha pesquisa (por esse motivo, ela não aparece neste texto grafada em itálico, marcação destinada aos termos nativos). Nesses termos, é possível conferir a ela o caráter de "invenção", no mesmo sentido que Wagner (2010) desenvolve suas reflexões sobre a "invenção da cultura": nem "cultura" e nem "onda" existem como entes discretos prontos a serem descobertos, investigados, interrogados, analisados; . A “onda de violência de 2012", assim, pode ser lida em termos de uma invenção da mídia. Não se trata, de forma alguma, de algo artificial, inexistente, falso ou cuja existência não é real. Pelo contrário, sua invenção lhe confere realidade (e efetividade). Antes, ela é uma forma criativa de lidar com o que já existe, de certa maneira, em excesso; é uma maneira de "tentar conferir um mínimo de ordem e inteligibilidade lá onde a plenitude da vida as dispensa completamente" (Goldman, 2011: 203). Se considero importante tornar evidente essa invenção, é justamente porque inventar a "onda” a fim de conferir ordem ao que estava ocorrendo não era uma preocupação das pessoas junto as quais realizei minha pesquisa. À narrativa de pretensão ordenadora sobre a “onda”, elas respon- 
diam com a multiplicidade criativa de suas vidas. E foi essa multiplicidade o que me foi oferecido a descrever.

É impressionante como uma abordagem tradicionalmente antropológica, já exposta por Lévi-Strauss, em 1958, e consagrada em escritos antropológicos sobre os mais diversos temas, cause estranhamento, indignação e até acusações morais quando empregada em um trabalho sobre tema tão controverso, tão presente no cotidiano e, por isso, de interesse comum não só para variadas áreas do conhecimento como também para diversos setores sociais. Falo da abordagem que acompanha a distinção entre antropologia ("ciência social do observado") e a sociologia ("ciência social do observador”), apontada por Lévi-Strauss (2003: 404). Essa diferenciação, embora não obedeça estritamente às delimitações disciplinares (há sociólogos fazendo ciência social do observado e antropólogos, do observador), traz implicações muito importantes. Uma delas é focar o PCC sem ter como metas apontar falhas ou tecer propostas para políticas de segurança pública, sem, sobretudo, ter como molde para minha descrição um ideal de Estado de Direito a partir do qual se classificaria o que está e o que não está em conformidade. Essas metas (e todos os vaticínios que não raro as acompanham) são próprias de uma "ciência social do observador" e, de uma perspectiva antropológica, esses trabalhos teriam muito mais a dizer sobre o próprio "Estado de Direito" ou sobre sua "segurança pública" do que sobre o PCC propriamente dito. Isso porque, por um lado, para apontar falhas ou criar propostas para as políticas de segurança pública, é preciso fazer do PCC um objeto de característica estatal (é o que se vê quando o classificam como “organização criminosa”). Só assim é possível lançar um olhar estatal sobre ele. Por outro lado, para criticar ou denunciar como perversidade as práticas daqueles sobre quem se escreve, é necessário cotejar os dados coletados em pesquisa com eventuais ideais democráticos. De um lado ou de outro, o procedimento é inserir na análise elementos que não condizem com o objeto que se pretende explicar. As explicações, nesse sentido, advêm muito mais desses elementos (do "observador") do que do próprio tema de pesquisa. Trata-se, em suma, de uma ciência social do (e sobre o) observador.

Diferentemente, perseguindo meu objetivo de realizar uma ciência social do observado, o tratamento analítico que conferi às cenas apresentadas acima não foi motivado pela tentativa de explicação da “onda de violência de 2012". Apesar do título, ela não foi o foco do problema, objetificado, cuja explicação seria buscada nos movimentos que compõem o PCC. Afinal, tomar a "onda" como unidade de 
análise reuniria arbitrariamente, sob uma liga externa aos acontecimentos, movimentos que se conectam de outras maneiras.

Evitei, também, uma comparação das diferentes cenas com as quais me deparei como se fossem unidades a serem cotejadas sob o espectro da "onda de violência". Diferentemente, conectei-as por meio de algumas noções que, articuladas e em constante diálogo, expressam uma maneira singular de conhecer e, sobretudo, viver o Crime. Essas conexões, contudo, foram realizadas por mim. Elas não provêm da malandragem e não são, portanto, o modo pelo qual os ladrões enxergaram a "onda de violência”. Isso porque, se cada posição no interior do movimento oferece uma vista singular, nenhum teve a mesma visão que o outro. Minha visão, como a deles, é singular. O que vi, portanto, foi apenas uma dentre as infinitas possibilidades. Como afirmei anteriormente, instalada no movimento, eu não via o que os malandros viam, mas via como eles viam. E é esse "como", são essas práticas de conhecimento que podem oferecer outra abordagem não somente acerca da "onda de violência de 2012”, como também de outros fenômenos relacionados ao PCC.

Recebido: 21/07/2018

Aprovado: 19/09/2018

Karina Biondi é bacharel em Ciências Sociais pela USP, mestre e doutora em Antropologia Social pela UFSCar. Atualmente, é professora na Universidade Estadual do Maranhão. Recebeu o prêmio de melhor livro da Association for Political and Legal Anthropology, seção da American Anthropology Association, com Sharing this Walk: An Ethnography of Prison Life and the PCC in Brazil, versão em inglês de Junto e misturado: uma etnografia do PCC. Também é autora de Proibido roubar na quebrada: território, lei e hierarquia e lei no PCC. Contato: ka.biondi@gmail.com

\section{Notas}

1. Este artigo é resultado de pesquisa de doutorado realizada no Programa de Pós-Graduação em Antropologia Social da Universidade Federal de São Carlos, com o apoio da Fundação de Amparo à Pesquisa do Estado de São Paulo. Agradeço aos professores Otávio Velho, John Comerford, Anna 
Catarina Morawska Vianna e Luiz Henrique de Toledo pela leitura e comentários precisos e estimulantes na ocasião da defesa da tese e ao Prof. Jorge Villela, pela orientação atenta e dedicada ao longo de minha pesquisa. Não posso também deixar de agradecer aos pareceristas anônimos pelas excelentes sugestões.

2. Na cidade de São Paulo, a taxa de homicídios passou de 52,58 por 100 mil habitantes em 1999 para 8,95 por 100 mil habitantes em 2011. Em 2012, essa taxa aumentou para 12,02 por 100 mil habitantes.

3. As palavras em itálico referem-se a termos e expressões utilizadas por aqueles sobre quem me dedico a escrever. Serão utilizadas aspas duplas para citações bibliográficas, enquanto as falas de meus interlocutores serão marcadas por aspas simples. Estas foram adequadas às normas do português escrito, com exceção daquelas cuja adequação violaria a estética e as ênfases pretendidas pelos locutores e, assim, descaracterizaria seu modo de expressão. Destaco que essas subversões linguísticas adotadas por meus interlocutores não denotam desconhecimento da norma culta, mas preferências estéticas.

4. Quebrada é um termo que corresponde a local de moradia, que pode ser atual, no caso dos que estão em liberdade, ou pode ser aquele em que reside sua família. Em alguns casos, também se refere ao local onde morou no passado e com o qual mantêm algum vínculo (afetivo ou financeiro, quando 'fecha com os caras de lá', ou seja, são parceiros nas atividades criminosas).

5. Ladrão é a forma como meus interlocutores se referem a quem pratica atividades criminosas, independente do tipo de atividades que desempenham. Essa é uma especificidade de São Paulo, onde o crime por excelência é o roubo (diferente do Rio de Janeiro, por exemplo, onde é o tráfico de drogas que tem essa centralidade).

6. Para as pessoas sobre as quais escrevo, salve diz respeito a uma espécie de orientação, de diretriz. Diferente, portanto, da tradução que costuma ser realizadas nos jornais, que se referem aos salves como leis ou ordens.

7. Neste caso, correria diz respeito a alguém que se dedica a atividades criminosas, sempre, contudo, com vistas a ganho material.

8. Malandro, para as pessoas entre as quais realizei pesquisa, tem uma conotação positiva (diferente de malandrão, que em geral pode ser entendido como um opressor). Neste caso, malandro diz respeito a alguém envolvido com o crime, embora nem sempre isso implique em desempenho de atividades ilegais ou ilícitas, mas sim com uma determinada forma de conduzir sua existência.

9. O PCC é também chamado, por meus interlocutores, de Comando, Partido, Família, Movimento, Quinze (em referência ao número 15.3.3, que anunciam a ordem de suas iniciais no alfabeto).

10. As informações entre parênteses são intervenções feitas pelo editor da reportagem; não compõem a fala do depoente, cuja identidade foi alterada neste texto para "interrogado", de forma a não dar mais repercussão para seu caso além da que já fora dada na mídia.

11. Uma sofisticada elaboração sobre a relação entre partes e todos e que inspirou minhas reflexões pode ser encontrada na obra de Marilyn Strathern. Segundo a autora, "um motivo para desejar que as coisas se encaixem repousa na suposição de que elas foram cortadas de algo" (Strathern, 2004: 109). 
12. Os debates são tratados pela mídia e por boa parte da literatura dedicada ao PCC como "tribunal do crime".

\section{Referências bibliográficas}

BERGSON, Henri. [1907] 2005. A evolução criadora. São Paulo: Martins Fontes.

BIONDI, Karina. 2010. Junto e Misturado: uma etnografia do PCC. São Paulo: Terceiro Nome. 2018. Proibido roubar na quebrada: território, hierarquia e lei no PCC. São Paulo: Terceiro

Nome.

BOAS, Franz. 1920. “The Social Organization of the Kwakiutl”. American Anthropologist, 22:111126.

CARAMANTE, André 2012a. "Baixada enfrenta nova onda de violência”. Folha de São Paulo, São Paulo, 18/04/2012. Disponível em: <http://www1.folha.uol.com.br/fsp/cotidiano/37872-baixada-enfrenta-nova-onda-de-violencia.shtml>. Acesso em: 14 jan. 2016.

. 2012b. “Três PMs são mortos em uma semana na zona leste”. Folha de São Paulo, São Paulo, 22/06/2012. Disponível em: < http://www1.folha.uol.com.br/fsp/cotidiano/ 50327-tres-pms-sao-mortos-em-uma-semana-na-zona-leste.shtml>. Acesso em: 17 dez. 2015.

DELEUZE, Gilles. [1985] 1992. Conversações. São Paulo: Editora 34.

DELPHINO, Plínio. 2012. "PCC também perde o controle dos comandados". Diário de São Paulo, São Paulo, 23/11/2012. Disponível em: < http://www.redebomdia.com.br/noticia/ detalhe $/ 38491 / \mathrm{PCC}+$ tambem + perde $+\mathrm{o}+$ controle + dos + comandados $>$. Acesso em: 23 jan. 2016.

GOLDMAN, Marcio. 2011. “O fim da antropologia”. Novos Estudos Cebrap, n. 89, mar.

JOZINO, Josmar. 2004. Cobras e Lagartos. Rio de Janeiro: Objetiva.

. 2012. "Rota mata seis e PMs são presos suspeitos de execução". Agora, São Paulo, 30/05/2012. Disponível em: <http://www.agora.uol.com.br/saopaulo/ult10103u1097654. shtml>. Acesso em: 23 jan. 2016.

LALANDE, André. [1926] 1999. Vocabulário técnico e crítico da filosofia. São Paulo: Martins Fontes. LÉVI-STRAUSS, Claude. [1958] 2003. "Lugar da antropologia nas ciências sociais e problemas colocados por seu ensino”. In: LÉVI-STRAUSS, C. (org.), Antropologia estrutural. Rio de Janeiro: Tempo Brasileiro.

MALINOWSKI, Bronislaw. 2016 [1922]. “Argonautas do Pacífico Ocidental”. In: CASTRO, CELSO (org). Textos básicos de antropologia. Cem anos de tradição: Boas, Malinowski, Lévi-Strauss e outros. Rio de Janeiro: Zahar.

MAUSS, Marcel. 2013 [1924-1925]. "Ensaio sobre a dádiva. Forma e razão da troca nas sociedades arcaicas”. São Paulo: Cosac Naify

SOBRINHO, Wanderley Preite. 2013. "Três meses após promessa, famílias de PMs assassinados estão sem indenização”. Último Segundo, IG, São Paulo, 28/01/2013. Disponível em: <http: / / ultimosegundo.ig.com.br/brasil/sp/2013-01-28/tres-meses-apos-promessa-familias-de-pms-assassinados-estao-sem-indenizacao.html>. Acesso em 23 jan. 2016. 
STOCKING, George. 1992. The Ethnographer's Magic and Other Essays in the History of Anthropology. Madison: University of Wisconsin Press.

STRATHERN, Marilyn. [1991] 2004. Partial Connections (Updated Edition). Walnut Creek: Altamira Press.

UOL. 2012. "Em 20 dias, 17 ônibus e 11 bases são atacadas em SP; 30 PMs e suspeitos são mortos”. UOL, São Paulo, 03/07/2012. Disponível em: <http://noticias.uol.com.br/cotidiano/ ultimas-noticias / 2012/07/03/em-20-dias-17-onibus-e-11-bases-sao-atacadas-em-sp-30-pms-e-suspeitos-sao-mortos.htm>. Acesso em 23 jan. 2016.

VILLELA, Jorge Mattar. 2010. “Apresentação”. In: BIONDI, Karina. Junto e Misturado: Uma etnografia do PCC. São Paulo: Terceiro Nome.

WAGNER, Roy. 2010. A Invenção da cultura. São Paulo, Cosac\&Naify. 
Resumo: Em 2012, ocorreu no Estado de São Paulo uma "onda de violência", atribuída a um confronto entre o Primeiro Comando da Capital (PCC) e a polícia. Após anos de queda no número de homicídios, a capital paulista apresentou um aumento de $40 \%$ com relação ao ano anterior. A pesquisa que origina este artigo foi realizada justamente durante esse período e se viu diante das dificuldades de, por um lado, etnografar uma “onda" e, por outro, se inserir em um debate cujos termos já estavam definidos de antemão. Este artigo aborda as questões implicadas na tentativa de se etnografar um movimento e expõe uma abordagem teórico-metodológica formulada face a essa experiência, bem como seus desenvolvimentos. A partir da exposição de situações de pesquisa, das dificuldades que impõem e dos recursos teórico-metodológicos acionados, procura-se abordar também a relação entre os materiais etnográficos e o conhecimento acadêmico produzido sobre eles.

Palavras-chave: Onda de violência - Primeiro Comando da Capital (PCC) - Movimento - Etnografia Teoria Antropológica - Metodologia
Abstract: In 2012, a "wave of violence" occurred in the State of São Paulo, attributed to a confrontation between the First Command of the Capital (PCC) and the police. After years of decline of the homicide numbers, this numbers increased a $40 \%$ over the previous year. This article is based on a research carried out precisely during this period. The challenges involved in this research were, on one hand, to make an ethnography of a wave and on the other hand, to enter in a debate whose bases were already defined. This article presents the challenges of an ethnography of a movement and exposes a theoretical-methodological approach formulated from this experience, as well its developments. From the exposition of the research conditions the difficulties found and the theoretical-methodological resources mobilized, this article also seeks to approach the relationship between ethnographical materials and academic knowledge produced on them.

Keywords: Wave of violence First Command of Capital - Movement - Ethnography -Anthropological Theory - Methodology 